\title{
Research on Cross-Cultural Adaptation Intervention with Big Data Analytics
}

\author{
Hui-jun $\mathrm{Ni}^{1, \mathrm{a}^{*}}$,Wei Zhang ${ }^{2, \mathrm{~b}}$ \\ ${ }^{1}$ Comprehensive Training Department State Grid of China Technology College Jinan, Shandong province, China \\ ${ }^{2}$ Jinan Campus Work Department State Grid of China Technology College Jinan, Shandong province, China
}

\begin{abstract}
With China's reform and opening up and the development of the One Belt and One Road, a series of cross-cultural adaptation problems such as language barriers and differences in customs and habits prevent international employees from obtaining timely and effective instrumental and expressive support. This article developed the three dimensions of academic adaptation, social culture and life adaptation and psychological adaptation and founded the current international employees generally had difficulties in cross-cultural adaptation. The result provided a helpful guideline to a cross-cultural adaptation.
\end{abstract}

\section{Introduction}

With China's reform and opening up and the development of the One Belt and One Road, as well as the improvement of China's overall education level, international partners come to strange countries as "residents". A series of cross-cultural adaptation problems such as language barriers and differences in customs and habits prevent them from obtaining timely and effective instrumental and expressive support. Some partners have been marginalized due to their inability to cope with cross-cultural adaptation issues, and their sense of self-identity and efficacy have been reduced ${ }^{[1]}$. This article relies on the practice of international employees in ordinary universities and enterprises, explores the dimensions of academic adaptation, social culture and life adaptation and psychological adaptation, and promotes the practice of International partners" cross-cultural adaptation $^{[1-3]}$.

\section{Literature Review and Statement of Hypothesis}

The conation of cross-cultural adaptation. Redfield (1936) pointed that cross-cultural adaptation was caused by two cultural patterns in the process of continuous contact with different cultural groups, and was the state of the subtle change to get better along between the two sides, and the difference is that for the degree of the change of different each other.

The problems of cross-cultural adaptation. Flannery (2001) believed that the process of intercultural adaptation is uni-dimensional, in which the object, in order to better adapt to the subject culture, gradually puts down the culture that the individual is familiar with, leaves behind

${ }^{*}$ missnihuijun@163.com

bzhangwei@163.com the previous understanding and cognition, and completely integrates into the new environment, so as to be fully assimilated by the subject culture. This process is continuous and unidirectional ${ }^{[2]}$. Berry (2002) put forward that the process of mutual adaptation, during which subject and object is not a single dimension, both sides have the tendency of cultural exchange, is blend in a culture, not at the cost of individual previous culture, which is the coexistence of can communication, so he for cross cultural adaptation, a two-dimensional model is put forward. Finally, in order to further improve the model, Piontkowski et al. (2005) comprehensively classified the social environment people live in into "core" and "periphery". The core part is that, even if the environment is constantly changing, the nature of this part is difficult to forget, while the periphery part is on the contrary.

The contributing factors of cross-cultural adaptation. Oberg K (1960) first put forward that the object into a new environment, will face to the four stages to adapt: honeymoon phase, crisis stage, recovery stage, adapt stage, which represents partners just coming into the new environment will not exist reaction immediately, fresh environment and culture, however, as the fresh recede, followed by homesick mood anxiety and discomfort, also creates a "cultural shock" phenomenon.Similarly, Ward C (1996) insisted that new partners around with the feelings of pleasure to environment, but as the curiosity gradually subsided, they have fewer resources, facing the greater change, adaption to the situation will be worse, as Ward found that the adaption to partners about early on the new environment of half a year has a high level than that of a year[3]. Yang Hongjun (2005) conveys that people have certain prejudices against cultures and styles of other countries. For example, we think that Germans are rigorous, Russians are tough, and Brazilians are 
passionate. Therefore, if individuals enter other countries with positive cognition, the situation of crosscultural adaptation will be more optimistic. On the contrary, individuals will have a difficult time in the subsequent adaptation process, which also adversely affects the stability of their social support network ${ }^{[4]}$.

Group work involved in cross-cultural adaptation. At present, the research on the adaptability of social workers involved in overseas groups mainly focuses on the analysis of the influencing factors behind the crosscultural adaptation of overseas workers from the professional perspective of social work. We will expand our social support network for overseas personnel. Wang Jianyu (2015) using quantitative research methods for analysis, summed up: the way of communication with others, the time length that life in China and Chinese proficiency is the most important influence its crosscultural adaptation of three, according to the analysis results, finally the article USES the method of case work and group work intervention of cultural social adaptability problems.Li Qian stressed that we should improve the adaptability of overseas students from multidimensional perspectives, guide them to rational cognition, stimulate their resilience in unfamiliar environment, teach them correct communication skills, and keep pace with The Times to give full play to the advantages of the Internet in expanding the social support system for overseas students. Feng Chao discussed and proved that the intercultural adaptation of overseas personnel has an important connection with their social support network ${ }^{[5]}$.

So, In order to have a clearer understanding of the subjects' intercultural adaptation, we assume:

H1: three dimensions of work adaptation, social life, cultural adaptation and psychological adaptation were measured.

According to the investigation, it is found that the subjects of the study generally have intercultural adaptation problems in the aspects of work adaptation, social life adaptation, cultural adaptation and psychological adaptation.Considering the universality of cross-cultural adaptation of Chinese nationals, the research adopts professional skills and models of group work to intervene in the phenomenon of cross-cultural discomfort. So, we assume:

$\mathrm{H} 2$ : The construction of social support network will enhance the level of intercultural adaptation

The lack of a stable social support network is also closely related to the confidence and positiveness of overseas students.In the process of contact with overseas people, I found that they are actually quite cheerful, but since they came to China, they can not adapt to the Chinese diet and living habits, and gradually become less confident. At the same time, they have no plan in life, which makes them sometimes very negative.

H3:The construction of self- confidence will enhance the level of intercultural adaptation

Overseas personnel before came to China for China knew little, stay in the Spring Festival, Chinese kung fu, pandas or one-sided understanding, such as the number of Chinese learning, for what people pursue with concept, almost don't understand China's modern history and culture, this also indirectly led to the students and the Chinese actual some unnecessary misunderstandings during the process of cross-cultural adaptation, learning Chinese culture will help the students a deeper understanding of China, also more familiar with the Chinese way of communication ${ }^{[6]}$.

So, we assume:

H4:The development of Chinese cultural cognition will enhance the level of intercultural adaptation.

In the actual process of intercultural adaptation, overseas people do not understand some behaviors of their partners, and sometimes they will be very angry and feel offended by their partners. But in fact, behind these situations, they often do not grasp the correct intercultural communication skills.In addition, due to the lack of understanding of Chinese customs and culture and the lack of a solid social support network, overseas people are unable to make rational and accurate judgments and reactions when confronted with difficulties in intercultural communication. Therefore, it has become one of the important requirements for overseas people to improve their intercultural communication skills.

H5:The application of fully communication training can enhance the level of intercultural adaptation.

The development of group work is a continuous and dynamic process, in which the group activity plan needs to be constantly improved. Also we assume:

H6:The intervention of team work as the parameter can enhance the level of intercultural adaptation.

\section{Questionnaire Design and Data Collection}

The research object. The research objects of this paper are the overseas employees from large enterprise groups, and there are 115 employees in China.Later, after a questionnaire survey of the overseas employee, we determined to intervene by working in a group.In the follow-up investigation and intervention work, we can fully understand the real life and working status of the research objects.

The development of group work is a continuous and dynamic process, in which the group activity plan needs to be constantly improved. The group name is "Intercultural Adaptation" growth group, 24 members, a total of 7 activities, through 6 stages, respectively is the group establishment stage, trust and cooperation stage, selfconfidence reconstruction stage, correct communication stage, familiar with China stage, active life stage. In addition, in order to improve the Chinese level of international students, Chinese will be the main communication language in this group work. The duration of the event is 1 year.

Effectiveness of clearly defined by Tansley ${ }^{[7]}$. The paper develops the schedules of intercultural adaptation and implements measurement instrument. The Cronbach's $\alpha$ is $0.892,0.79,0.84$, all above 0.7 . 


\subsection{Reliability and Validity}

To ensure reliability and validity of research tools, this study adopts scale as used in the existing literature, and carries through appropriate modification in aim of present study. The standardized coefficients of each observed variable are more than 0.75 , the AVE value of each variable is than 0.5 , and the square root of AVE variables are greater than the correlation coefficient of the variable with other variables, which indicates the variables have good introverted validity and discriminate validity.

\subsection{Hypothesis Testing}

The paper uses the LISREL 8.70 software for data analysis. We can read the results in table1, table 2 and table 3 .

Table1. Reliability and validity analysis

\begin{tabular}{lrrr}
\hline \multicolumn{1}{c}{ Variable } & $\mathbf{1}$ & $\mathbf{2}$ & $\mathbf{3}$ \\
\hline Work adaptation & 0.87 & & \\
Social life cultural adaptation & 0.31 & 0.78 & \\
Psychological adaptation & 0.34 & 0.31 & 0.86 \\
Cronch $(\alpha)$ & 0.87 & 0.88 & 0.95 \\
\hline
\end{tabular}

Li Qian emphasized that the international students' adaptability should be improved from multi-dimensional perspectives. By guiding the international students' rational cognition, the resilience of the international students in the unfamiliar environment should be aroused, the correct communication skills should be taught, and the advantages of the Internet should be brought into play to expand the social support system for the international students.Feng Chao discussed and proved that there is an important relationship between the intercultural adaptation of international students and their social support network, and concluded that the closer the social support network of African students coming to China is, the more helpful it will be for their social and cultural adaptation and psychological adaptation (Feng Chao, 2014).Starting from the psychological situation of international students, Wang Yu proved the relationship between the adaptation of international students, the sense of belonging of school and mental health, and finally pointed out that group work can improve the mental health of international students by improving the level of adaptation and the sense of belonging of school (Wang Yu, 2019).

Table2. The results of assumptions

\begin{tabular}{|c|c|c|c|}
\hline $\begin{array}{l}\text { Vari- } \\
\text { able }\end{array}$ & $\begin{array}{l}\text { Standard } \\
\text { value }\end{array}$ & $\begin{array}{c}T \\
\text { value }\end{array}$ & Results \\
\hline$\overline{\mathrm{H} 2}$ & $\begin{array}{l}\text { The level of intercultural adaptation } 0.77 \\
\leftarrow \text { The The construction of social } \\
\text { support network }\end{array}$ & 0.86 & yes \\
\hline H3 & $\begin{array}{l}\text { The level of intercultural adaptation } \leftarrow 0.77 \\
\text { The construction of self- confidence }\end{array}$ & 0.89 & yes \\
\hline H4 & $\begin{array}{l}\text { The level of intercultural adaptation } 0.48 \\
\leftarrow \text { The development of Chinese } \\
\text { cultural cognition }\end{array}$ & 1.81 & yes \\
\hline
\end{tabular}

H5 The level of intercultural adaptation $\leftarrow 0.761 \quad 6.64$ yes
The application of fully
communication training
0.96
$0.87 \quad 0.41$

Cronch 0.90

(a)

Chi-Square $=132.45, \mathrm{df}=81, \mathrm{RMSEA}=0.052, \mathrm{NFI}=0.91, \mathrm{NNFI}=0.98$, $\mathrm{CFI}=0.96, \mathrm{IFI}=0.96, \mathrm{GFI}=0.90, \mathrm{AGFI}=0.85$

The influence of group service on intercultural adaptation.Working group in the process of cross-cultural adaptive adjustment, team through all-round adjustment, gradually show the positive influence on China culture in honeymoon phase, the crisis stage, recovery stage, adapt stage, has realized the people in China to expand the social support network, strengthen the confidence of life attitude, acquisition at the beginning of intercultural communication skills, more familiar with Chinese customs culture service effect.In this process, social workers play the role of patient listener and professional guide, which makes them the most powerful part in the process of intercultural adaptation of overseas people.

Table3. The results of work-team assumptions

\begin{tabular}{|c|c|c|c|}
\hline $\begin{array}{l}\text { Vari- } \\
\text { able }\end{array}$ & $\begin{array}{c}\text { stamption } \\
\text { value }\end{array}$ & $\begin{array}{c}\mathrm{T} \\
\text { value }\end{array}$ & Results \\
\hline H6 & $\begin{array}{l}\text { The level of intercultural adaptation } 0.77 \\
\text { in honeymoon phase } \leftarrow \text { The } \\
\text { activities of the work team. }\end{array}$ & 0.78 & yes \\
\hline H61 & $\begin{array}{l}\text { The level of intercultural adaptation } 0.77 \\
\text { inthe crisis stage } \leftarrow \text { The activities of } \\
\text { the work team }\end{array}$ & 0.82 & yes \\
\hline H62 & $\begin{array}{l}\text { The level of intercultural adaptation } 0.48 \\
\leftarrow \text { The activities of the work team }\end{array}$ & 1.85 & yes \\
\hline H63 & $\begin{array}{l}\text { The level of intercultural adaptation } 0.761 \\
\text { in recovery stage } \leftarrow \text { The activities of } \\
\text { the work team }\end{array}$ & 7.42 & yes \\
\hline H64 & $\begin{array}{l}\text { The level of intercultural adaptation } 0.761 \\
\text { in adapt stage } \leftarrow \text { The activities of } \\
\text { the work team }\end{array}$ & 5.86 & yes \\
\hline \multicolumn{2}{|c|}{$\begin{array}{ll}\text { Cronch } 0.90 & 0.96 \\
(\text { a }) & \end{array}$} & 0.91 & 0.52 \\
\hline \multicolumn{4}{|c|}{$\begin{array}{l}\text { Chi-Square }=132.45, \mathrm{df}=81, \mathrm{RMSEA}=0.052, \mathrm{NFI}=0.91, \mathrm{NNFI}=0.98, \\
\mathrm{CFI}=0.96, \mathrm{IFI}=0.96, \mathrm{GFI}=0.90, \mathrm{AGFI}=0.85\end{array}$} \\
\hline
\end{tabular}

\section{Conclusion and Discussion}

Different conclusions can be drawn from the advantage perspective or the problem perspective when it comes to intercultural adaptation in China. When viewed from a problem perspective, it is often assumed that an individual needs to be "treated" by a "doctor" to get out of the pain.The dominant perspective, on the other hand, advocates that the difficulties faced by individuals are not due to their own factors, but just happen to encounter difficulties on the way of growth. The conclusion of this study also supports this view.

The process of intercultural adaptation that is inevitable for overseas people to come to China can also be regarded as the process of rebuilding their social support system. Social support, as a collection of many others who can provide individuals with instrumental and expressive support, plays a strong positive role in helping individuals rebuild rational cognition of themselves and their environment (Caplan G, 1974). When the individual presents the negative emotions of anxiety, excitement or 
tension, the positive psychological reaction given by social support can alleviate the adverse reaction of the individual and bring positive influence to the individual, that is, the society and the individual are interrelated in the process of psychological reaction.Social work agencies, as professional organizations, can play a particularly important role in social support.

Social workers play a guiding role in the process of international students' intercultural adaptation.Since neither side of cross-cultural communication understands that cross-cultural communication requires skills, social workers take on the role of one

The role of the mentor enables both sides to develop their own awareness of intercultural communication and gradually enhance their intercultural communication ability.

Social workers play the role of communicator in the process of international students' intercultural adaptation.Influenced by their respective growing environment, both communicators often have certain stereotypical impressions of each others customary cultural customs.In the process of communication, these misunderstandings always cannot be fully revealed for mutual reflection ${ }^{[8]}$. At this time, the social worker acts as a bridge of communication between the two parties, guiding them to bravely tell each other their cultural prejudices, so as to make people honest and find out their unreasonable cognition and correct it in time.

Social workers play a supporting role in the process of intercultural adaptation of international students. In the actual process of intercultural communication, it is difficult for overseas people to find a suitable person to listen to their feelings.At this time, social workers can well play the role of supporters, give them sincere attention and encouragement, build mutual trust, and continue to provide emotional support.

\section{References}

1. Quan Haijin, He Yingsi. (2019). Research on Big Data Information Processing Technology based on Cloud Computing (English) [J].Machine bed and Liquid Pressure, 47 (24) : 118-124.

2. Dehua Ju, Beijun Shen. (2012). Internet of Knowledge Plus Knowledge Cloud - A Future Education Ecosystem[J]. IERI Procedia.

3. Caplan G. The family as a support system[M]. CAPLAN G, KILLILEA $M$.

4. Flannery W P, Reise S P, Yu J .An empirical comparison of acculturation models[J].Personality and Social Psychology Bulletin, 2001(27):1035 1045

5. Oberg K, Culture Shock: Adjustment to New Cultural Evironmrnt[J]. Practical Anthropology, 1960, 7(4):177-182

6. .International Journal of Intercultural Relations, 2005 (29):251-272 [33]

7. Ward C, Okura Y, Kennedy A, et al. The U-Curve on trial: a longitudinal study ofpsychological and sociocultural adjustment during Cross-Cultural transition[J]. International Journal of Intercultural Relations, 1998, 22(3):277-291

8. Mell P M , Grance T . (2011). SP 800-145. The NIST Definition of Cloud Computing[M]. National Institute of Standards \& Technology. 